\title{
ANALISIS MODEL SIMPANG NGAPEMAN MENGGUNAKAN PROGRAM SIMULASI PTV VISSIM
}

\author{
Berlian Fikkriatur Rizqiah $^{1)}$, Budi Yulianto ${ }^{2)}$, Setiono ${ }^{3)}$ \\ 1) Mahasiswa Program Studi Teknik Sipil, Fakultas Teknik, Universitas Sebelas Maret \\ 2) \&3) Pengajar Program Studi Teknik Sipil, Fakultas Teknik, Universitas Sebelas Maret \\ J1. Ir. Sutami 36A, Surakarta 57126. Telp.0271-634524. Email: berlianrizqiah@student.uns.ac.id
}

\begin{abstract}
Jalan Brigjend Slamet Riyadi is an arterial road in Surakarta City with many activity centers. The number of activity centers in the Central Business District (CBD) area causes various types of vehicles to cross the road. In this study, an analysis of the performance of the Ngapeman Intersection which is one of the intersections located on Jalan Brigjend Slamet Riyadi is carried out by being modeled using the PTV Vissim simulation program. The purpose of this study was to microsimulate traffic flow at Simpang Ngapeman under conditions mixed traffic by performing calibration (using the GEH method for traffic volume) and validation (using t-test for queue length and relative difference test for travel time) between the model and the as well as the existing conditions in the field. The result of this study is that the model has been calibrated with a GEH value of less than five $(G E H<5)$ and validated by the value of the $t$-test, it is found that t count is smaller than $t$ table and $P$ (two-tailed) is greater than 0.05 so it can be said that the model in the Vissim PTV simulation program, the conditions in the field are close.
\end{abstract}

Keywords: Intersection Performance, Ngapeman, Vissim

\begin{abstract}
Abstrak
Jalan Brigjend Slamet Riyadi merupakan jalan arteri Kota Surakarta dimana terdapat banyak pusat kegiatan di dalamnya. Banyaknya pusat kegiatan pada daerah Central Business District (CBD) mengakibatkan berbagai jenis kendaraan melintasi jalan tersebut. Pada kajian ini dilakukan analisis kinerja Simpang Ngapeman yang merupakan salah satu simpang yang terdapat pada Jalan Brigjend Slamet Riyadi dengan dimodelkan dengan menggunakan program simulasi PTV Vissim. Tujuan dari penelitian ini adalah untuk melakukan mikrosimulasi arus lalu lintas di Simpang Ngapeman pada kondisi mixed traffic dengan melakukan kalibrasi (menggunakan metode GEH untuk volume lalu lintas) dan validasi (menggunakan uji t untuk panjang antrean dan uji perbedaan relatif untuk waktu perjalanan) antara model dan juga kondisi eksisting di lapangan. Hasil dari kajian ini adalah model sudah terkalibrasi nilai GEH kurang dari lima $(\mathrm{GEH}<5)$ dan tervalidasi dengan nilai dari uji t didapatkan thitung lebih kecil dari t tabel dan P (two tailed) lebih besar dari 0,05 sehingga dapat dikatakan bahwa model pada program simulasi PTV Vissim sudah mendekati kondisi di lapangan.
\end{abstract}

Kata Kunci : Kinerja Simpang, Ngapeman, PTV Vissim

\section{PENDAHULUAN}

Jalan Brigjend Slamet Riyadi merupakan jalan arteri Kota Surakarta dimana terdapat banyak pusat kegiatan di dalamnya. Banyaknya pusat kegiatan pada daerah Central Business District (CBD) mengakibatkan berbagai jenis kendaraan melintasi jalan tersebut khususnya sepeda motor. Berdasarkan Unit Pengelolaan Pendapatan Daerah (UPPD) Kota Surakarta terdapat 26.891 kendaraan bermotor baru yang telah diregistrasi pada tahun 2019 (BPS Surakarta,2020). Banyaknya jenis kendaraan pada jalan raya menunjukkan bahwa terdapat lalu lintas campuran (mixed traffic) sesuai dengan kondisi jalanan di Indonesia.

Simpang yang merupakan area kritis tempat bertemunya beberapa ruas jalan dapat menimbulkan konflik pergerakan dan kemacetan apabila tidak dilakukan pengaturan pada simpang. Pada kajian ini dilakukan analisis model mixed traffic Simpang Ngapeman yang merupakan salah satu simpang yang terdapat pada Jalan Brigjend Slamet Riyadi menggunakan program simulasi PTV Vissim. Selanjutnya dilakukan kalibrasi dan validasi antara model dan kondisi eksisting di lapangan. Pada kalibrasi digunakan variabel volume lalu lintas menggunakan metode Geoffrey E. Havers $(\mathrm{GEH})$ dan untuk validasi digunakan variabel panjang antrean menggunakan uji $\mathrm{t}$ dan waktu perjalanan menggunakan uji perbedaan relatif.

\section{METODE}

\section{Pengumpulan Data}

Lokasi yang diambil untuk penelitian ini adalah Simpang Ngapeman yang menghubungkan ruas Jalan Brigjend Slamet Riyadi (lengan barat dan timur), ruas Jalan Gajah Mada (lengan utara), dan ruas Jalan Honggowongso (lengan selatan). Data yang didapatkan dari survei di lapangan berupa geometri jalan, volume dan komposisi lalu 
lintas, proporsi kendaraan membelok, panjang antrean, dan waktu perjalanan. Survei dilakukan pada pukul 07.0009.00 WIB dan didapatkan jam puncak yaitu pada pukul 07.30-08.30 WIB.

\section{Pemodelan dengan PTV Vissim}

PTV Vissim merupakan program mikrosimulasi untuk melakukan perencanaan, analisis, dan optimasi lalu lintas yang mampu melakukan simulasi untuk kendaraan pribadi, transportasi umum, aliran lalu lintas multimoda dan rekayasa pedestrian yang dapat dikalibrasi berdasarkan perilaku masing-masing. Fellendorf dan Vortisch (2010) menentukan bahwa PTV Vissim sebagai simulasi mikro bergantung pada tiga blok penyusun dan satu blok hasil simulasi sebagai berikut:

1. blok infrastruktur untuk membuat model infrastruktur lalu lintas seperti jalan raya, rel, fasilitas parkir, jalur transportasi publik, dan lain-lain. Pada menu Network Objects terdapat elemen untuk memodelkan infrastruktur seperti link, connector, dan objek lain seperti detektor, lokasi berhenti kendaraan, dan lampu lalu lintas,

2. blok lalu lintas untuk memodelkan lalu lintas yang menyusun kendaraan umum dan kendaraan pribadi. Setiap kategori kendaraan pribadi memiliki spesifikasi teknis tertentu yang dapat didefinisikan sendiri seperti panjang kendaraan, lebar, tingkat akselerasi dan perlambatan, dan kecepatan maksimum,

3. blok kontrol yang berisi elemen untuk melakukan kontrol lalu lintas yang berupa pengaturan signal control, signal groups, signal heads, dan signal time tables,

4. blok output yang menangani semua jenis output data.

Model dibuat berdasarkan kondisi aktual yang terjadi di lapangan menggunakan program simulasi PTV Vissim. Parameter driving behavior yang digunakan pada simulasi adalah sebagai berikut: average standstill distance bernilai 0,5 meter, desired position at free flow: any, checklist observe adjecent lane, minimum lateral distance standing bernilai 0,2 meter. Terdapat perbedaan parameter dari yang digunakan pada penelitian Putri dan Irawan (2015) yaitu pada average standstill distance bernilai 0,6 meter. Selanjutnya dilakukan kalibrasi dan validasi dilanjutkan dengan mengambil kesimpulan.

\section{Kalibrasi}

Kalibrasi adalah proses untuk menyesuaikan kondisi simulasi dengan kondisi lapangan dengan parameter yang disesuaikan sehingga didapatkan model lalu lintas yang menyerupai dengan kondisi di lapangan. Proses kalibrasi dapat dilakukan berdasarkan perilaku pengemudi daerah yang diamati, tinjauan jaringan jalan, dan asal tujuan pergerakan. Variabel yang digunakan dalam kalibrasi adalah volume lalu lintas yang diukur menggunakan metode GEH. Nilai GEH dihitung menggunakan persamaan [1] dan didapatkan kesimpulan sesuai dengan Tabel 1.

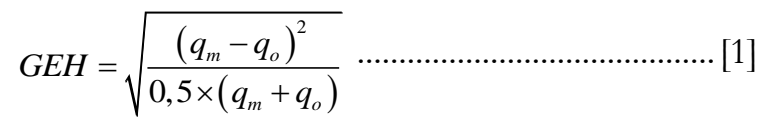

Keterangan:

$\mathrm{q}_{\mathrm{m}}=$ arus lalu lintas hasil model

qo $\quad=$ arus lalu lintas hasil observasi

Hasil Perhitungan Rumus GEH menurut Oregon Department of Transportation (2011) dapat disimpulkan sebagai berikut:

- nilai GEH < 5,0 model diterima,

- nilai GEH diantara 5,0 sampai 10,0 model error atau data buruk, dan

- nilai GEH > 10,0 model ditolak.

\section{Validasi}

Validasi merupakan proses untuk menentukan apakah model simulasi lalu lintas yang dibuat dapat merepresentasikan kenyataan yang ada dengan akurat. Model dikatakan valid apabila output yang didapatkan dari model mendekati data observasi di lapangan. Pada penelitian ini variabel yang digunakan untuk validasi adalah waktu perjalanan dan panjang antrean. Selanjutnya dilakukan pengolahan data dengan uji T untuk panjang antrean dan uji perbedaan relatif untuk waktu perjalanan. 
Uji T bertujuan untuk menguji kebenaran atau kepalsuan hipotesis nihil $\left(\mathrm{H}_{0}\right)$ yang menyatakan bahwa diantara dua buah mean sampel yang diambil secara random dari populasi yang sama tidak terdapat perbedaan yang signifikan (Sudjono, 2010). Uji T memiliki kaidah pengujian sebagai berikut:

- $\mathrm{H}_{0}$ diterima apabila $\mathrm{t}_{\text {hitung }}<\mathrm{t}_{\text {tabel }}$

- $\mathrm{H}_{0}$ ditolak apabila thitung $>\mathrm{t}_{\text {tabel }}$

Berikut adalah rumus thitung:

$$
t=\frac{\bar{x}_{1}-\bar{x}_{2}}{s \sqrt{\frac{1}{n_{1}}+\frac{1}{n_{2}}}}
$$

Keterangan:

$\bar{x}_{1}=$ mean data set pertama

$\bar{x}_{2}=$ mean data set kedua

$\mathrm{n}_{1} \quad=$ jumlah data pada set pertama

$\mathrm{n}_{2} \quad=$ jumlah data pada set kedua

$\mathrm{S} \quad=$ varian dengan rumus pada persamaan

$$
S=\sqrt{\frac{\left(n_{1}-1\right) \mathrm{S}_{1}^{2}+\left(n_{2}-1\right) \mathrm{S}_{2}^{2}}{n_{1}+n_{2}-2}}
$$

Uji perbedaan relatif adalah perbedaan yang ukurannya dengan membandingkan nilai perbedaan mutlak dengan nilai observasi sehingga tidak memiliki satuan. Nilai perbedaan mutlak dapat dihitung dengan persamaan berikut: Perbedaan Relatif $=\frac{\text { NilaiModel }- \text { NilaiObeservasi }}{\text { NilaiObservasi }}$.... [4]

\section{HASIL DAN PEMBAHASAN}

\section{Rekapitulasi Data}

Berikut adalah data-data yang didapatkan dari hasil survei di lapangan yang selanjutnya digunakan sebagai parameter dalam membuat model dalam PTV Vissim. Proporsi pergerakan kendaraan pada Simpang Ngapeman disajikan dalam tabulasi tiap lengan simpang (lihat Tabel 1.) dan komposisi lalu lintas dapat dilihat pada Gambar 1.

Tabel 1. Proporsi pergerakan kendaraan dalam persen

\begin{tabular}{cccccccc}
\hline \multirow{2}{*}{ Jenis Kendaraan } & \multicolumn{3}{c}{ Barat } & \multicolumn{2}{c}{ Utara } & \multicolumn{2}{c}{ Selatan } \\
\cline { 2 - 8 } & Kiri & Lurus & Kanan & Kiri & Lurus & Lurus & Kanan \\
\hline MC & 0,15 & 0,75 & 0,10 & 0,09 & 0,91 & 0,62 & 0,38 \\
LV & 0,13 & 0,76 & 0,11 & 0,14 & 0,86 & 0,65 & 0,35 \\
LV & 0,14 & 0,86 & 0,00 & 0,00 & 1,00 & 0,00 & 1,00 \\
BUS & 0,00 & 1,00 & 0,00 & 0,00 & 0,00 & 1,00 & 0,00 \\
\hline
\end{tabular}




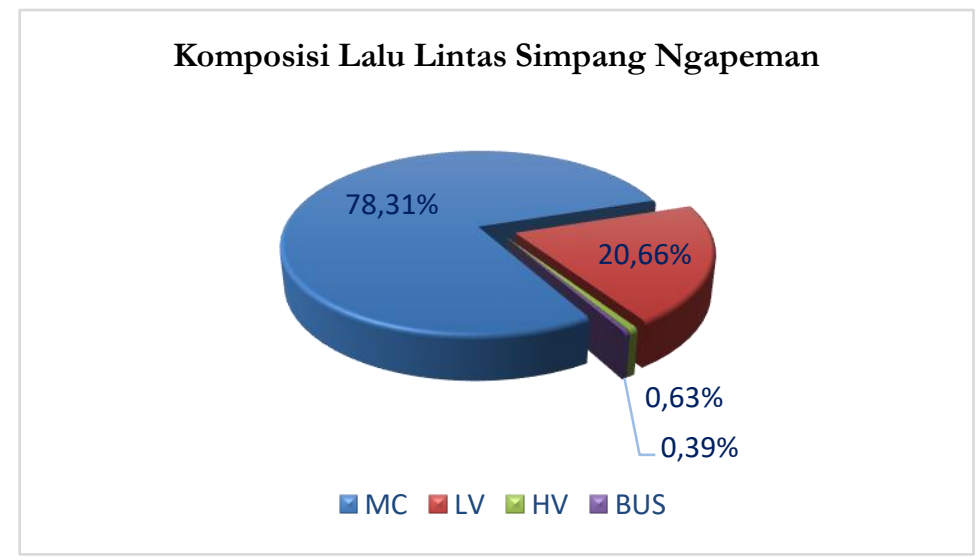

Gambar 1. Komposisi lalu lintas simpang ngapeman

Setelah dilakukan run pada model selanjutnya didapatkan output berupa volume kendaraan, panjang antrean, dan waktu perjalanan. Berikut adalah hasil kalibrasi volume lalu lintas antara hasil observasi dan model pada Simpang Ngapeman yang sudah diuji dengan metode GEH pada Tabel 2 dan hasil validasi model pada Tabel 3 dan Tabel 4.

Tabel 2. Hasil kalibrasi arus model

\begin{tabular}{|c|c|c|c|c|c|c|c|c|c|c|}
\hline \multirow{3}{*}{\multicolumn{2}{|c|}{ Arus Lalu Lintas }} & \multicolumn{6}{|c|}{ q Model } & \multirow{3}{*}{ q Observasi } & \multirow{3}{*}{ Nilai GEH } & \multirow{3}{*}{ Keterangan } \\
\hline & & \multicolumn{5}{|c|}{ Run ke- } & \multirow{2}{*}{ Rata-rata } & & & \\
\hline & & 1 & 2 & 3 & 4 & 5 & & & & \\
\hline Barat & & 3343 & 3419 & 3334 & 3309 & 3342 & 3349 & 3327 & 0.38 & Diterima \\
\hline Utara & Masuk & 1884 & 1983 & 1975 & 1886 & 2011 & 1948 & 1925 & 0.52 & Diterima \\
\hline Selatan & & 579 & 550 & 583 & 574 & 582 & 574 & 571 & 0.13 & Diterima \\
\hline Utara & & 806 & 749 & 794 & 797 & 822 & 794 & 828 & 1.19 & Diterima \\
\hline Selatan & Keluar & 1904 & 1991 & 1984 & 1909 & 1951 & 1948 & 2079 & 2.92 & Diterima \\
\hline Timur & & 2842 & 2693 & 2734 & 2734 & 2737 & 2748 & 2923 & 3.29 & Diterima \\
\hline
\end{tabular}

Tabel 3. Hasil validasi panjang antrean

\begin{tabular}{|c|c|c|c|c|c|c|c|c|}
\hline \multirow[t]{2}{*}{ No. } & \multirow{2}{*}{$\begin{array}{l}\text { Lengan } \\
\text { Simpang }\end{array}$} & \multirow{2}{*}{$\begin{array}{c}\text { Interval Menit } \\
\text { ke- }\end{array}$} & \multicolumn{2}{|c|}{$\begin{array}{l}\text { Panjang antrean } \\
\text { Maksimum }\end{array}$} & \multirow[t]{2}{*}{ T hitung } & \multirow[t]{2}{*}{ T tabel } & \multirow[t]{2}{*}{$\mathbf{P}$} & \multirow[t]{2}{*}{ Keterangan } \\
\hline & & & Model & Observasi & & & & \\
\hline \multirow{6}{*}{1} & \multirow{6}{*}{ Barat } & 07:40:00 & 82 & 129 & \multirow{6}{*}{1.397} & \multirow{6}{*}{2.228} & \multirow{6}{*}{0.193} & \multirow{6}{*}{ OK } \\
\hline & & 07:50:00 & 106 & 106 & & & & \\
\hline & & 08:00:00 & 133 & 110 & & & & \\
\hline & & 08:10:00 & 144 & 120 & & & & \\
\hline & & 08:20:00 & 173 & 108 & & & & \\
\hline & & 08:30:00 & 194 & 115 & & & & \\
\hline \multirow{6}{*}{2} & \multirow{6}{*}{ Utara } & $07: 40: 30$ & 95 & 101 & \multirow{6}{*}{0.782} & \multirow{6}{*}{2.228} & \multirow{6}{*}{0.453} & \multirow{6}{*}{ OK } \\
\hline & & $07: 50: 30$ & 137 & 172 & & & & \\
\hline & & 08:00:30 & 161 & 143 & & & & \\
\hline & & 08:10:30 & 182 & 138 & & & & \\
\hline & & $08: 20: 30$ & 166 & 145 & & & & \\
\hline & & 08:30:30 & 186 & 150 & & & & \\
\hline
\end{tabular}

Pada Tabel 3 ditunjukkan bahwa hasil thitung pada seluruh lengan simpang kurang dari tabel dan nilai $\mathrm{P}$ (two tailed) $>$ 0,05 sehingga dapat dikatakan bahwa tidak terdapat perbedaan yang signifikan antara panjang antrean maksimum hasil output model dan panjang antrean maksimum dari hasil observasi lapangan.

Tabel 4. Hasil validasi waktu perjalanan

\begin{tabular}{cccccc}
\hline \multirow{2}{*}{ No. } & $\begin{array}{c}\text { Asal-Tujuan } \\
\text { Perjalanan }\end{array}$ & \multicolumn{2}{c}{$\begin{array}{c}\text { Waktu Perjalanan } \\
\text { Rata-rata (detik) }\end{array}$} & $\begin{array}{c}\text { Persentase } \\
\text { Perbedaan Relatif }\end{array}$ & Keterangan \\
\cline { 3 - 4 } & Model & Observasi & & \\
\hline 1 & Barat-Timur & 240 & 210 & $14 \%$ & Diterima \\
\hline
\end{tabular}


Hasil kesesuaian untuk parameter waktu perjalanan hasil uji diterima apabila nilai perbedaan relatif kurang dari 15\%. Pada Tabel 4 diperlihatkan nilai perbedaan relatif adalah 14\% sehingga menunjukkan bahwa model dikatakan valid.

\section{SIMPULAN}

Dari kajian yang telah dilakukan didapatkan hasil yaitu model Simpang Ngapeman yang disimulasikan menggunakan PTV Vissim sudah terkalibrasi dan tervalidasi. Arus lalu lintas pada model telah terkalibrasi dengan menggunakan metode GEH dan didapatkan hasil yaitu model dapat diterima karena nilai GEH kurang dari lima. Untuk panjang antrean telah tervalidasi menggunakan uji $t$ dan didapatkan hasil berupa $t$ hitung kurang dari $t$ tabel dan P (two tailed) lebih dari 0,05 sehingga dapat disimpulkan bahwa tidak terdapat perbedaan yang signifikan antara panjang antrean maksimum hasil output model dan panjang antrean maksimum dari hasil observasi. Pada uji perbedaan relatif hasil uji juga diterima dengan nilai perbedaan relatif sebesar $14 \%$ sehingga model dapat dikatakan valid.

\section{REFERENSI}

Fellendorf, M., \& Vortisch, P, 2010, "Microscopic traffic flow simulator VISSIM In Fundamentals of traffic simulation”, Springer, pp. 63-93, New York.

Irawan, M.Z., \& Putri, N.H., 2015, "Kalibrasi Vissim Untuk Mikrosimulasi Arus Lalu Lintas Tercampur pada Simpang Bersinyal (Studi Kasus: Simpang Tugu, Yogyakarta)", Jurnal Penelitian Transportasi Multimoda Vol 3 No. 3, pp. 97-106. Universitas Gajah Mada. Yogyakarta

Oregon, D., 2011, "Protocol for VISSIM simulation. Oregon Department of Transportation", Oregon Departement of Transportation. USA.

Papageorgiou, M., Diakaki, C., Dinopoulou, V., Kotsialos, A., \& Wang, Y., 2003, "Review of road traffic control strategies", Proceedings of the IEEE Vol. 91, No. 12, pp. 2043-2067.

Sudijono, A., 2010, “Pengantar Statistik Pendidikan”, Rajawali Press. Jakarta. 